\title{
Inclusão escolar de crianças e adolescentes com paralisia cerebral em escolas/classes regulares
}

\author{
Inclusion of children and adolescents with cerebral palsy in regular schools/classes
}

José Salomão Schwartzman ${ }^{1}$

As discussões que cercam a inclusão de pessoas com vários tipos de deficiências, entre elas as com Paralisia Cerebral (PC), têm se caracterizado por inúmeros equívocos.

O que me parece um equívoco inicial é a forma como são interpretadas as várias leis e normas em vigor no Brasil. No caso específico do Decreto 3.298, de 20 de dezembro de $1999^{(1)}$, diferentemente do que tem sido defendido, entendendo-se que esse decreto torna obrigatória a inclusão de pessoas com deficiência em escolas regulares, podemos observar na seção II, Do Acesso à Educação, artigos 24 e 25, que em várias instâncias é garantido o direito ao acesso a instituições especializadas, quando o ensino regular não oferece condições adequadas ao ensino dessas pessoas.

\section{Seção II - Do Acesso à Educação}

Art. 24. Os órgãos e as entidades da Administração Pública Federal direta e indireta responsáveis pela educação dispensarão tratamento prioritário e adequado aos assuntos objeto deste Decreto, viabilizando, sem prejuízo de outras, as seguintes medidas:

I - a matrícula compulsória em cursos regulares de estabelecimentos públicos e particulares de pessoas portadoras de deficiência capazes de se integrar na rede regular de ensino.

(...)

$\S 1^{\circ}$ Entende-se por educação especial, para os efeitos deste Decreto, a modalidade de educaşão escolar oferecida preferencialmente na rede regular de ensino para educando com necessidades educacionais especiais, entre eles o portador de deficiência.

Art. 25. Os serviços de educação especial serão ofertados nas instituições de ensino público ou privado do sistema de educação geral, de forma transitória ou permanente, mediante programas de apoio para o aluno que está integrado no sistema regular de ensino, ou em escolas especializadas exclusivamente quando a educação das escolas comuns não puder satisfazer as necessidades educativas ou sociais do aluno ou quando necessário ao bem-estar do educando.

Como pode ser observado nos trechos grifados (grifos nossos), o decreto recomenda a inclusão escolar de pessoas com PC, desde que encontrem na escola/classe regular as condições necessárias ao seu aprendizado acadêmico.

Conhecendo-se as condições dos estabelecimentos de ensino em nosso país, bem como a enorme variabilidade dos quadros clínicos na PC, fica evidente que a discussão sobre a melhor colocação dessas pessoas nas escolas não pode ter caráter ideológico, mas deve levar em conta alguns pressupostos fundamentais: Quem é esse indivíduo? Quais são suas características pessoais? Que tipo de PC apresenta e, principalmente, qual o grau de comprometimento funcional? Quais as características gerais do estabelecimento de ensino que essa pessoa frequenta(rá)?

No que se refere às características da pessoa com PC, é imprescindível levar em conta o grau de prejuízo motor que apresenta. Claro que, quanto mais severo o comprometimento, maior será a necessidade de o estabelecimento de ensino oferecer condições de acessibilidade física e dispor de tecnologias que permitam ao aluno superar, o tanto quanto possível, suas dificuldades. Para os indivíduos mais comprometidos, o uso de computadores, adaptações das interfaces para seu uso adequado e mesmo equipamentos mais sofisticados, como tecnologias eye-tracking, serão necessários. A imensa maioria das escolas no Brasil, sejam elas
1Doutor em Medicina na área de Neurologia pela Universidade Federal de São Paulo; Professor Titular do Curso de Pós-graduação em Distúrbios do Desenvolvimento da Universidade Presbiteriana Mackenzie; Diretor Clínico da Associação Brasileira da Síndrome de Rett, São Paulo, SP, Brasil
Endereço para correspondência:

José Salomão Schwartzman

Rua França Pinto, 941 - Vila Mariana

CEP 04016-034 - São Paulo/SP

E-mail: josess@terra.com.br

Conflito de interesse: nada a declarar

Recebido em: 6/6/2011 
públicas ou privadas, não dispõe desses equipamentos, nem seus professores estão adequadamente habilitados para fazer o melhor uso dos mesmos.

Uma variável que não pode deixar de ser considerada é a presença de comorbidades, dentre as quais é imprescindível ressaltar a importância das habilidades intelectuais. É óbvio que alunos com PC que apresentam graus significativos de deficiência intelectual e deficiências sensoriais (visuais e/ou auditivas) importantes representam enormes desafios em uma classe regular de ensino. Tenho acompanhado inúmeros alunos com variados tipos de deficiências que, "incluídos" por vários anos em escolas/classes regulares, não deixam apenas de aprender, mas também de ter a oportunidade de ser ensinados em ambiente pedagógico mais adequado às suas necessidades.

Lamentavelmente, a discussão sobre a inclusão escolar de pessoas com deficiência assumiu, em nosso país, características de um embate entre aqueles que defendem a "inclusão" imediata e irrestrita e aqueles que propõem um verdadeiro processo de educação mais responsável, no qual se reconhece o direito, mas não a obrigatoriedade, dessas pessoas de frequentarem uma escola regular. Nessa discussão, perde-se de vista o que deveria ser o cerne da questão, que é discutir qual seria o ambiente pedagógico mais favorável a cada indivíduo.

Não há qualquer dúvida de que vários alunos com PC demonstram capacidade de acompanhar o currículo escolar regular, mas não se pode ignorar aqueles que não o conseguem, embora permaneçam “incluídos” por vários anos, sem qualquer tipo de ganho acadêmico.

Alguns defensores da inclusão irrestrita tentam demonstrar as suas vantagens, apontando para os ganhos que a presença de um aluno com necessidades especiais traria para os colegas com desenvolvimento típico, uma vez que estes aprenderiam a conviver com as diferenças. O que se questiona é o custo, para os indivíduos com deficiência, determinado por essa sua exposição nem sempre bem cuidada, que passa a fazer o papel de programas socioeducativos para incentivo do respeito às diferenças.
Defensores da política da inclusão irrestrita têm conseguido desativar várias escolas e instituições especializadas no atendimento de pessoas cujo grau de comprometimento funcional é de tal ordem que necessitam de ambientes altamente especializados e capacitados. Recentemente, assistimos à tentativa de desativação do atendimento especializado a pessoas com deficiência visual e auditiva em instituições do estado do Rio de Janeiro, praticada por funcionária do MEC a qual exigia que, a partir de então, esses indivíduos fossem absorvidos na rede regular de ensino. Atitudes autoritárias desse tipo têm se repetido aqui, na capital do estado de São Paulo, e têm resultado no encerramento efetivo das atividades de várias instituições.

Do ponto de vista do atendimento às necessidades educativas de todo alunado, o que se deve procurar é a disponibilização de uma gama de instituições de ensino, de tal modo que os responsáveis pelo aluno possam fazer escolhas racionais sobre o tipo de escola que parece ser o mais adequado ao seu filho. Pais de crianças com desenvolvimento típico têm à sua disposição escolas com as mais variadas filosofias e métodos de ensino, com diversas localizações e estruturas físicas, e podem escolher, de acordo com suas convicções, sobre o que deve ser melhor para suas crianças. Por que negar a pais de crianças com PC ou com qualquer outra deficiência esse direito de escolha? Afinal de contas, quem se dá o direito de decidir, em nome da sociedade, qual escola é a melhor para todos?

Grupos que defendem de forma radical a inclusão irrestrita confundem "escola para todos" com "todos na mesma escola”, e esse equívoco deve ser evitado. Em outras palavras, nas condições atuais do ensino brasileiro, grande parte das crianças com PC não encontra condições mínimas que lhes permitam frequentar a escola regular, pela falta de acessibilidade, de metodologias que atendam às suas necessidades, de tecnologias que otimizem o seu aprendizado, de capacitação efetiva de professores e demais funcionários da escola e de condições mínimas para uma verdadeira inclusão social.

\section{Referências bibliográficas}

1. Brasil - Presidência da República. Decreto $n^{\circ} 3.298$ de 20 de dezembro de 1999. Brasília: Presidência da República; 1999. 